\title{
Strategi Pengembangan Usaha Produk UD. Amelia Bakery Tabanan Strategy Product Development UD. Amelia Bakery
}

\author{
Ni Luh Wayan Ari Sukarmini, L.P Wrasiati*, I Wayan Gede Sedana Yoga. \\ PS Teknologi Industri Pertanian, Fakultas Teknologi Pertanian, Universitas Udayana, Kampus Bukit \\ Jimbaran, Badung, Kode pos : 80361; Telp/Fax : (0361) 701801
}

Diterima 23 Maret 2021 / Disetujui 23 Juni 2021

\begin{abstract}
UD. Amelia Bakery is a business that is engaged in food, especially bread and cakes. Amelia Bakery located Jl.Tukad Sang-sang, Banjar Dinas Sanggulan 2 No.1 Jadi Anyar, Kediri District, Tabanan Regency. Amelia Bakery produce brownies and muffins. The high competition is one of the factors to carry out product development strategies. The purpose of thisstudy are: 1) To determine theinternal (strengths and weakness) and external (opportunities and threats) factorsfaced in marketing at UD. Amelia Bakery, 2) Determining alternative strategies that can be used for product business development at UD. Amelia Bakery, 3) Determine the priority of product business development strategies at UD. Amelia Bakery. This study uses the SWOT method to determine the alternative strategies used, and TOPSIS to rank these alternatives. The strategies that can be applied in UD. Amelia Bakery Tabanan is a strategy to hold and maintain, where the alternative strategies are as follows: a) Improve product quality, b) Increase the variety or type of product being promoted, c) Maintain consistency of product quality, d) Training for employees, e) Making packaging that is more attractivet.
\end{abstract}

Keywords : UD. Amelia Bakery, brownies and muffins, SWOT analysis, TOPSIS Method.

\section{ABSTRAK}

UD. Amelia Bakery merupakan sebuah usaha yang bergerak di bidang makanan khususnya roti dan kue. Amelia Bakery berlokasi Jl.Tukad Sang-sang, Banjar Dinas Sanggulan 2 No.1 Jadi Anyar, Kecamatan Kediri, Kabupaten Tabanan. Amelia Bakery memproduksi brownies dan muffin. Persaingan yang ketat merupakan salah satu faktor dalam melakukan strategi pengembangan produk. Tujuan penelitian ini adalah: 1) Untuk mengetahui faktor internal (kekuatan dan kelemahan) dan eksternal (peluang dan ancaman) yang dihadapi dalam pemasaran di UD. Amelia Bakery, 2) Menentukan alternatif strategi yang dapat digunakan untuk pengembangan bisnis produk UD. Amelia Bakery, 3) Menentukan prioritas strategi pengembangan bisnis produk di UD. Amelia Bakery. Penelitian ini menggunakan metode SWOT untuk menentukan strategi alternatif yang digunakan dan TOPSIS menentukan perangkingan untuk dapat memutuskan pemilihan strategi terbaik. Strategi yang bisa diterapkan di UD. Amelia Bakery Tabanan merupakan strategi untuk pertahanan dan pelihara, dimana alternatif strategi adalah sebagai berikut: a) Meningkatkan kualitas produk, b) Meningkatkan variasi atau jenis produk yang dipromosikan, c) Menjaga konsistensi kualitas produk, d) Pelatihan pengolahan produksi untuk tenaga pengolahan produksi, e) Membuat kemasan yang lebih menarik. Kata kunci : UD. Amelia Bakery, brownies dan muffins, analisis SWOT, metode TOPSIS.

*Korespondensi Penulis:

Email: wrasiati@unud.ac.id 


\section{PENDAHULUAN}

\begin{tabular}{llcr}
\multicolumn{2}{c}{ Kelangsungan } & hidup & suatu \\
perusahaan & dituntut & untuk & dapat \\
menyesuaikan & dengan & perubahan & kondisi
\end{tabular} yang terjadi pada saat sekarang ini. Usaha agar dapat mengikuti perubahan dan menyesuaikan dengan perkembangan dilakukan secara menyeluruh mulai dari produksi dan pemasaran. Produksi produk yang berkualitas, unik dan mengikuti perkembangan jaman yang didukung oleh pemasaran yang kuat akan mampu mempertahankan kehidupan perusahaan. Pemasaran dalam suatu perusahaan merupakan faktor yang penting dan turut menentukan kelangsungan hidup bagi suatu perusahaan, sebab kegagalan dalam memasarkan barang akan berakibat fatal. Penerapan strategi pemasaran yang tepat dan efektif, perusahaan juga harus dapat menyesuaikan dengan kondisi pasar yang dihadapi oleh perusahaan, sehingga strategi pemasaran dapat berhasil. Ketika para konsumen dihadapkan dengan banyak pilihan untuk setiap keputusan membeli yang mereka buat, kebutuhan para penjual adalah membangun hubungan yang kuat dengan para pelanggan.

Tingginya persaingan ini menjadi salah satu faktor untuk melakukan strategi pengembangan produk dan pemasaran (Yodharya, 2013). Oleh sebab itu, perlu dilakukan analisis faktor internal dan eksternal untuk mengetahui kekuatan dan kelemahan yang dimiliki, serta dapat memanfaatkan peluang dan mewaspadai ancaman yang dihadapi agar dapat menghadapi pesaing (Juliani, 2017). UD. Amelia Bakery merencanakan pengembangan usahanya karena banyak usaha sejenis yang menjadi pesaing, sehingga perlu dilakukan penelitian "Strategi Pengembangan Usaha Produk UD. Amelia Bakery Tabanan" dimana nantinya akan memberikan suatu rekomendasi strategi pengembangan produk. Penerapan sebuah strategi pengembangan produk yang tepat merupakan tuntutan bagi perusahaan agar mampu mengembangkan usaha dan dapat bertahan dari persaingan (Isabela, 2018).

Adapun tujuan dari penelitian ini adalah, 1) Untuk mengetahui faktor internal (kekuatan dan kelemahan) dan eksternal (peluang dan ancaman) yang dihadapi dalam pemasaran di UD. Amelia Bakery, 2) Menentukan alternatif strategi yang dapat digunakan untuk pengembangan usaha produk di UD. Amelia Bakery, 3) Menentukan prioritas strategi pengembangan usaha produk pada UD.Amelia Bakery. Manfaat dari penelitian ini adalah Hasil penelitian ini diharapkan dapat memberikan informasi bagi pelaku bisnis Brownies dan Muffin mengenai kondisi perusahaan, meliputi proses produksi dan manajemen perusahaan, sebagai kebijakan keputusan perusahaan, serta sebagai bahan pertimbangan dalam menyusun strategi pengembangan usaha produk untuk produk yang akan dihasilkan.

\section{METODE PENELITIAN}

\section{Tempat dan waktu pelaksanaan}

Penelitian ini dilaksanakan pada UD. Amelia Bakery salah satu pembuatan brownies dan muffin yang berlokasi di Jl.Tukad Sang-sang Land 2 No.1 Jadi Anyar Kec.Kediri Tabanan Bali.Waktu penelitian akan dilakukan dari bulan Januari sampai Februari 2019.

\section{Alat dan Bahan Peneitian}

Data yang digunakan dalam penelitian ini adalah data primer yang diperoleh melalui wawancara langsung dengan pihak internal perusahaanya itu pemilik UD. Amelia Bakery. Data primer juga didapatkan melalui observasi di lokasi usaha serta pihak-pihak yang bersangkutan dengan UD. Amelia Bakery. Metode survei pada penelitian ini menggunakan teknik 
wawancara mendalam (depth-interview), dengan mengadakan Tanya jawab secara terbuka dengan responden tentang objek permasalahan yang diteliti. Materi wawancara dipandu oleh instrument penelitian berupa kuisioner.

\section{Pelaksanaan Penelitian}

Tahapan dan analisis pada penelitian ini, yaitu: analisis lingkungan peusahaan dengan menggunakan matriks IFE dan EFE, dilanjutkan dengan tahap pencocokan menggunakan matriks IE dan SWOT (David, 2009), tahap yang terakhir adalah tahap pencocokan dengan menggunakan metode TOPSIS (Yoon dan Hwang, 1981). Matriks IFE untuk mengevaluasi faktor-faktor internal pada UD. Amelia Bakery berkaitan dengan kekuatan dan kelemahan yang dianggap penting. Matriks EFE untuk mengevaluasi faktor-faktor eksternal UD. Amelia Bakery berkaitan dengan peluang dan ancaman yang dianggap penting. Tahapan dari matriks IFE dan EFE, yaitu: identifiaksi faktor internal perusahaan, dilanjutkan dengan wawancara dengan responden, penentuan bobot, dilanjutkan dengan penentuan peringkat, perhitungan nilai tertimbang (weighted score), perhitungan total nilai tertimbang (total weghted score). Matriks IE didasari pada dua dimensi kunci yaitu total nilai IFE pada sumbu $X$ dan total nilai EFE yang diberi bobot pada sumbuY. Terdapat beberapa tahap dalam penentuan strategi yang dibangun melalui matriks SWOT. Berdasarkan penelitian Abiddin (2017), tahap pengambilan keputusan untuk menentukan strategi yang paling sesuai adalah dengan menggunakan metode TOPSIS. Langkah-langkah penelitian dengan metode TOPSIS, yaitu: 1) Mendefinisikan permasalahan yang akan diselesaikan dengan metode TOPSIS; 2) Membuat matriks keputusan normalisasi; 3) Membuat matriks keputusan yang ternormalisasi terbobot. Matriks keputusan ternormalisasi terbobot; 4)
Menentukan solusi ideal positif dan solusi ideal negatif ; 5) Menentukan jarak antara nilai terbobot setiap alternative terhadap solusi ideal positif dan solusi ideal negatifnya. Untuk menentukan jarak antara nilai terbobot terhadap setiap alternative solusi ideal positif; 6) Menghitung nilai preferensi untuk setiap alternatif dengan persamaan.

\section{HASIL DAN PEMBAHASAN}

\section{Analisis Lingkungan Perusahaan}

Pada tahap input pengolahan data dilakukan dengan menggunakan matriks IFE dan matriks EFE. Tahap ini meringkas informasi dasar yang dibutuhkan untuk merumuskan alternatif strategi. Berikut merupakan hasil analisis matriks IFE dan matriks EFE dari Amelia Bakery Kabupaten Tabanan.Hasil analisis matriks IFE dapat dilihat pada Tabel 1 dan hasil analisis matriks EFE dapat dilihat pada Tabel 2.

Berdasarkan Tabel 1 menunjukkan bahwa Amelia Bakery memiliki faktor kekuatan pertama yaitu produk yang diproduksi tanpa menggunakan bahan pengawet dengan nilai 0,456 karena kualitas merupakan hal penting bagi konsumen untuk membeli produk. Kualitas produk yang bagus akan mempengaruhi jumlah pembeli yang datang ke Amelia Bakery. Kelemahan utama yang dimiliki oleh Amelia Bakery adalah kurangnya pelatihan karyawan dengan nilai 0,280. Menurut Safitri et al.(2017) Rosana Bakery memiliki dua kekuatan utama yang memiliki nilai 0,36 yaitu memiliki produk yang rasanya enak dibandingkan produk lainnya dan produk disortir seebelum dipasarkan. Rosana Bakery juga memiliki kelemahan utama yang memiliki nilai 0,24 yaitu kurangnya kegiatan promosi. 
Tabel 1. Hasil AnalisisMatrisk IFE pada UD. Amelia Bakery

\begin{tabular}{|c|c|c|c|}
\hline Kekuatan (A) & $\begin{array}{l}\text { Bobot } \\
\text { (a) }\end{array}$ & $\begin{array}{l}\text { Rating } \\
\text { (b) }\end{array}$ & $\begin{array}{l}\text { Nilai } \\
(\mathbf{c}=\mathbf{a} * \mathbf{b})\end{array}$ \\
\hline $\begin{array}{l}\text { Memiliki produk yang rasanya enak dan bertekstur } \\
\text { lembut }\end{array}$ & 0.127 & 3.2 & 0.406 \\
\hline Memiliki produk yang harganya terjangkau & 0.106 & 3.0 & 0.317 \\
\hline $\begin{array}{l}\text { Produk yang diproduksi tanpa menggunakan bahan } \\
\text { pengawet }\end{array}$ & 0.127 & 3.6 & 0.456 \\
\hline Pengiriman produk tepat waktu & 0.106 & 3.0 & 0.317 \\
\hline $\begin{array}{l}\text { Komunikasi terjalin baik antara pemilik usaha dengan } \\
\text { karyawan }\end{array}$ & 0.106 & 3.0 & 0.317 \\
\hline \multicolumn{4}{|l|}{ Kelemahan (B) } \\
\hline Kurangnya pelatihan karyawan & 0.100 & 2.8 & 0.280 \\
\hline Promosi pemasaran masih kurang & 0.107 & 2.4 & 0.257 \\
\hline Peralatan produksi sebagian masih manual & 0.107 & 2.2 & 0.236 \\
\hline Kurangnya inovasi terhadap produk baru & 0.107 & 2.2 & 0.236 \\
\hline Total IFE $(A+B)$ & 1.000 & & 2.847 \\
\hline
\end{tabular}

Tabel 2. Hasil Analisis Matriks EFE dari UD. Amelia Bakery

\begin{tabular}{llll}
\hline Peluang & $\begin{array}{l}\text { Bobot } \\
\text { (a) }\end{array}$ & $\begin{array}{l}\text { Rating } \\
\text { (b) }\end{array}$ & $\begin{array}{l}\text { Nilai } \\
(\mathbf{c = a} \text { *b) }\end{array}$ \\
\hline Pertumbuhan jumlah penduduk yang sangat cepat & 0.138 & 2.4 & 0.332 \\
\hline Pertumbuhan pasar yang tinggi & 0.146 & 2.6 & 0.380 \\
\hline Loyalitas konsumen & 0.163 & 3.0 & 0.488 \\
\hline Pemasaran melalui media sosial (medsos) & 0.179 & 3.2 & 0.572
\end{tabular}

\begin{tabular}{llll}
\hline Ancaman & & & \\
\hline Kenaikan harga bahan baku & 0.163 & 2.0 & 0.325 \\
\hline Daya beli konsumen menurun & 0.098 & 2.4 & 0.234 \\
\hline Banyaknya pesaing produk sejenis & 0.114 & 2.2 & 0.250 \\
\hline & & & \\
\hline Total & $\mathbf{1 . 0 0 0}$ & & $\mathbf{2 . 5 8 2}$ \\
\hline
\end{tabular}

Berdasarkan tabel Matriks EFE diproleh total nilai terbobot sebesar 2,582. Peluang utama yang dimiliki UD. Amelia
Bakery adalah pemasaran melalui sosial media seperti facebook dan instagram dengan nilai sebesar 0,572. Ancaman utama yang 
yang dihadapi UD. Amelia Bakery yaitu kenaikan harga bahan baku dengan nilai sebesar 0,325. Menurut (Setiadji dan Harjanti, 2013) banyaknya perusahaan yang retatif sama dengan harga yang bersaing menyebabkan pembeli memiliki pilihan produk yang banyak, sehingga pembeli dengan mudah berpindah dari suatu perusahaan ke perusaan lainnya. Menurut Safitri et al.(2017) peluang utama yang dimiliki Rosana Bakery adalah loyalitas konsumen dengan nilai 0,49. Ancaman utama yang dihadapi oleh Rosana Bakery yaitu banyak pesaing produk sejenis dengan varian topping rasa dan desain kemasan yang lebih menarik dengan nilai sebesar 0,24.

\section{Matriks IE (Internal Eksternal)}

Berdasarkan pemetaan pada matriks IE, dapat dilihat bahwa pada sumbu-x matriks IE, nilai total IFE adalah 2,847 sedangkan pada sumbu-y matriks IE, nilai total EFE adalah 2,582. Hasil dari Matriks IE menunjukan bahwa UD. Amelia Bakery Tabanan berada pada sel $\mathrm{V}$ matriks IE. Strategi yang lazim digunakan untuk perusahaan yang berada pada sel $\mathrm{V}$ adalah strategi pertahanan dan pelihara (Hold \& Maintain), penetrasi pasar, pengembangan produk dan pengembangan pasar merupakan dua strategi yang banyak dilakukan apabila perusahaan berada dalam sel V. Matriks IE dapat dilihat pada Gambar 1.

\begin{tabular}{|c|c|c|c|}
\hline $\mathrm{IFE}=2,847$ & $\begin{array}{c}\text { Kuat } \\
3,0-4,0\end{array}$ & $\begin{array}{r}\text { Rata-rata } \\
\text { 2,0-2,99 }\end{array}$ & $\begin{array}{l}\text { Lemah } \\
1,0-1,99\end{array}$ \\
\hline $\begin{array}{r}\text { Tinggi } \\
3,0-4,0\end{array}$ & I & II & III \\
\hline $\begin{array}{l}\text { Sedang } \\
2,0-2,99\end{array}$ & IV & $\mathrm{V}$ & VI \\
\hline $\begin{array}{l}\text { Rendah } \\
1,0-1,99\end{array}$ & VII & VIII & IX \\
\hline
\end{tabular}

Gambar 1. Hasil Analisis Matriks IE pada UD. Amelia Bakery

\section{Matriks Strengths, Weakness, Opportunities, and Threaths (SWOT)}

Analisis SWOT merupakan suatu kerangka analisis yang terintegrasi antara internal perusahaan dan lingkungan eksternal, dengan membangun pendekatan SWOT (Assauri, 2013). Setelah mengetahui posisi UD. Amelia Bakery dan didapatkan inti strategi berdasarkan kekuatan, kelemahan, peluang dan ancaman, maka dapat diformulasikan alternatif strategi (Rangkuti, 2005). Berdasarkan analisis SWOT pada Tabel 3, alternatif strategi yang akan digunakan oleh UD. Amelia Bakery untuk mengembangkan usahanya, yaitu:

Alternatif Strategi yang diperoleh dimasukkan ke dalam strategi yang telah dirumuskan pada matriks IE yaitu pertahanan dan pelihara (hold \& maintain), yaitu:

1. Strategi Penetrasi Pasar

Mempromosikan UD. Amelia Bakery ke sosial media (WO2).

2. Strategi Pengembangan Produk

Pelatihan pengolahan/produksi untuk tenaga pengolahan/produksi (WO1),

memperbanyak varian/jenis produk yang dipromosikan (SO2), meningkatkan kualitas produk (SO1), membuat kemasan yang lebih 
menarik dari produk lainnya (WT1), mempertahankan dan menjaga konsistensi mutu produk (S03).

3. Strategi Pengembangan Pasar Memperluas pemasaran produk Amelia
Bakery (ST1), bekerjasama dengan perusahaan sejenis untuk mempertahankan suplay bahan baku (ST2), menguatkan kerjasama dengan pihak pemasok (WT2).

Tabel 3. Hasil Perumusan Strategi di UD. Amelia Bakery Tabanan

\begin{tabular}{|c|c|c|}
\hline Eksternal & $\begin{array}{l}\text { Faktor Kekuatan/ Strenght }(\mathrm{S}) \\
\text { Memiliki produk yang rasanya } \\
\text { enak dan bertekstur lembut } \\
\text { Memiliki produk yang harganya } \\
\text { terjangkau } \\
\text { Produk yang diproduksi tanpa } \\
\text { menggunakan bahan pengawet } \\
\text { Pengiriman produk tepat waktu } \\
\text { Komunikasi terjalin baik antara } \\
\text { pemilik usahadengan karyawan }\end{array}$ & $\begin{array}{l}\text { Faktor Kelemahan/ Weakness }(\mathrm{W}) \\
\text { Kurangnya pelatihan karyawan } \\
\text { Promosi pemasaran masih kurang } \\
\text { Peralatan produksi sebagian masih } \\
\text { manual } \\
\text { Kurangnya inovasi terhadap produk } \\
\text { baru }\end{array}$ \\
\hline $\begin{array}{l}\text { Faktor Peluang/Opurtunites }(\mathrm{O}) \\
\text { Pertumbuhan jumlah penduduk } \\
\text { yang sangat cepat } \\
\text { Pertumbuhan pasar yang tinggi } \\
\text { Loyalitas konsumen } \\
\text { Pemasaran melalui sosial } \\
\text { media seperti facebook dan } \\
\text { instagram }\end{array}$ & $\begin{array}{l}\text { S-O } \\
\text { Meningkatkan kualitas produk } \\
(\mathrm{S} 1, \mathrm{~S} 2, \mathrm{~S} 3, \mathrm{O} 1, \mathrm{O} 2, \mathrm{O} 3) \\
\text { Memperbanyak varian/jenis } \\
\text { produk yang dipromosikan } \\
(\mathrm{S} 1, \mathrm{~S} 2, \mathrm{~S} 3, \mathrm{O} 2,03) \\
\text { Mempertahankan dan menjaga } \\
\text { konsistensi mutu produk } \\
(\mathrm{S} 4, \mathrm{~S} 5,04)\end{array}$ & $\begin{array}{l}\text { W-O } \\
\text { Pelatihan pengolahan/produksi } \\
\text { untuk tenaga pengolahan/produksi } \\
\text { (W1,W2,W3) } \\
\text { Mempromosikan } \\
\text { UD. Amelia Bakery kesosial media } \\
\quad(\mathrm{W} 4, \mathrm{O} 1, \mathrm{O} 2, \mathrm{O} 3, \mathrm{O} 4)\end{array}$ \\
\hline $\begin{array}{l}\text { Faktor Ancaman/ Treath }(\mathrm{T}) \\
\text { Kenaikan harga bahan baku } \\
\text { Daya beli konsumen menurun } \\
\text { Banyaknya pesaing produk } \\
\text { sejenis }\end{array}$ & $\begin{array}{l}\text { S-T } \\
\text { Memperluas pemasaran produk } \\
\text { Amelia Bakery } \\
(\mathrm{S} 1, \mathrm{~S} 2, \mathrm{~S} 3, \mathrm{~S} 4, \mathrm{~T} 2, \mathrm{~T} 3) \\
\text { Bekerjasama dengan perusahaan } \\
\text { sejenis untuk mempertahankan } \\
\text { suplay bahan baku } \\
\text { (S5,O1) }\end{array}$ & $\begin{array}{l}\text { W-T } \\
\text { Membuat kemasan yang lebih } \\
\text { menarik dari produk lainnya } \\
\text { (W2, W4,T2, T3) } \\
\text { Menguatkan kerjasama dengan } \\
\text { pihak pemasok } \\
(\mathrm{W} 1, \mathrm{~W} 2, \mathrm{~T} 1)\end{array}$ \\
\hline
\end{tabular}

Tabel 4. Alternatif Matriks SWOT di UD. Amelia Bakery Tabanan

\begin{tabular}{ll}
\hline Alternatif & Keterangan \\
\hline A1 & Meningkatkan kualitas produk \\
A2 & Memperbanyak varian/jenis produk yang dipromosikan \\
A3 & Mempertahankan dan menjaga konsistensi mutu produk \\
A4 & Pelatihan pengolahan/produksi untuk tenaga pengolahan/produksi \\
A5 & Membuat kemasan yang lebih menarikdari produk lainnya \\
\hline
\end{tabular}

Strategi yang telah didapatkan dari hasil analisis SWOT dijadikan sebagai alternatif-alternatif keputusan dalam metode TOPSIS. Alternatif strategi dapat dilihat pada
Tabel 4. Berdasarkan hasil perangkingan alternatif yang telah dirumuskan pada matriks IE, dapat diketahui bahwa alternatif strategi ketiga memiliki nilai preferensi sebesar 
0,680, karena dapat mempertahankan dan menjaga konsistensi mutu produk. Hal ini juga di dukung oleh Trisnayanti et al. (2019) tentang strategi pengembangan produk agroindustri pada area belanja di agrowisata cau chocolate factory, berdasarkan hasil perangkingan alternatif, diketahui bahwa alternatif strategi kelima karena nilai preferensi tertinggi yaitu sebesar 0,629, dapat diambil keputusan utama bahwa alternatif kelima yaitu memperluas pemasaran produk olahan cokelat. Alternatif strategi lain yang bisa digunakan diperusahaan adalah alternative ketiga yaitu melakukan promosi produk-produk olahan cokelat ke sosial media dengan nilai preferensi sebesar 0,605 dan alternati strategi keempat yaitu memperkuat kerjasama dengan pemasok dan antar pelaku pariwisata dan perusahaan sejenis dengan nilai preferensi sebesar 0,600. Hasil perangkingan alternatif pada UD. Amelia Bakery dapat dilihat pada Gambar 2.

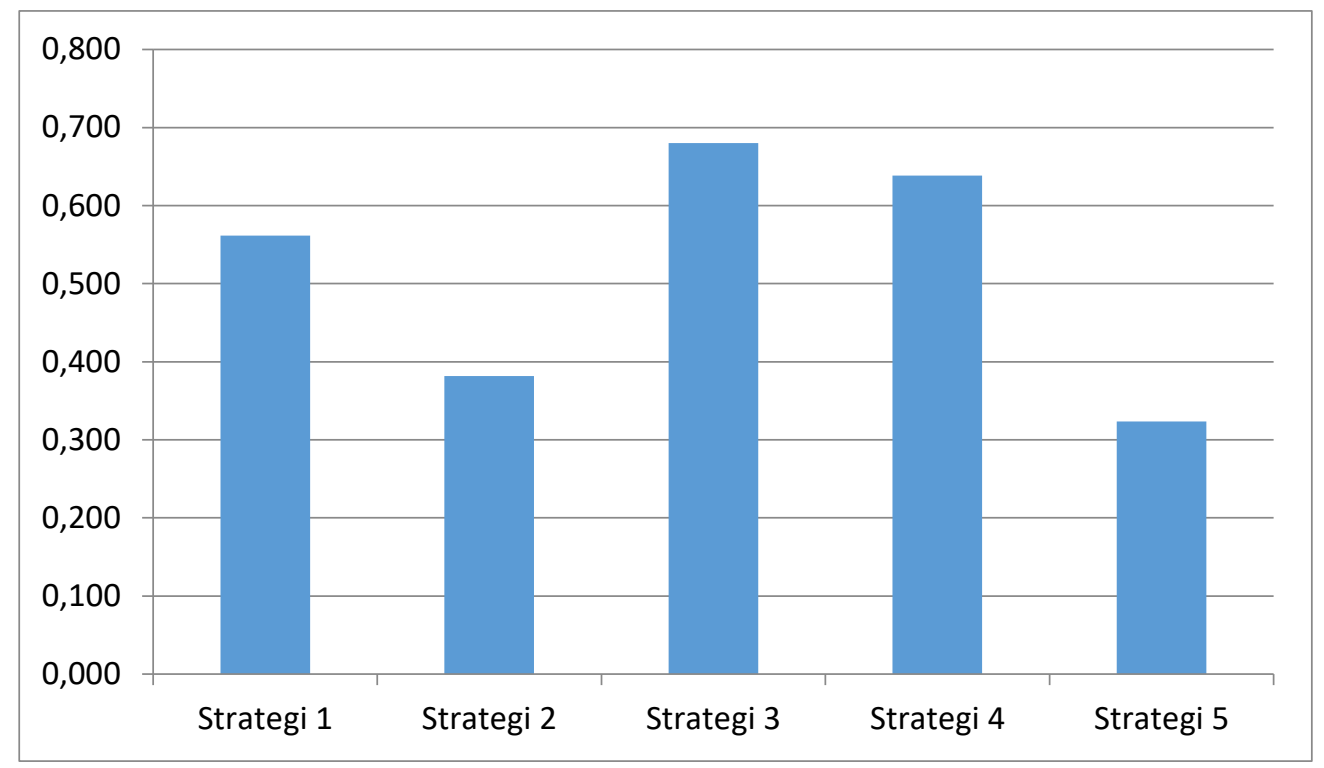

Gambar 2. Hasil Perangkingan Alternatif pada UD. Amelia Bakery.

\section{KESIMPULAN DAN SARAN}

\section{Kesimpulan}

Berdasarkan penelitian yang telah dilakukan maka dapat disimpulkan beberapa hal sebagai berikut:

1. Faktor Internal (kekuatan dan kelemahan) yang dihadapi oleh UD. Amelia Bakery yaitu : kekuatan, a) Memiliki produk yang rasanya enak dan bertekstur lembut, b) Memiliki produk yang bernilai ekonomis, c) Produk yang diproduksi tanpa menggunakan bahan pengawet, d) Pengiriman produk tepat waktu, e) Komunikasi terjalin baik antara pemilik usaha dengan karyawan. Kelemahannya, a) Kurangnya pelatihan karyawan, b)
Sistem pemasaran masih kurang, c) Peralatan produksi sebagian masih manual, d) Pesanan produk dari konsumen lemah.

2. Faktor Eksternal (peluang dan ancaman) yang dihadapi UD. Amelia Bakery Tabanan yaitu : peluang, a) Pertumbuhan jumlah penduduk yang sangat cepat, b) Pertumbuhan pasar yang tinggi, c) Loyalitas konsumen, d) Pemasaran melalui sosial media seperti facebook dan instagram. Ancaman, a) Kenaikan harga bahan baku, b) Daya beli konsumen menurun, c) Banyaknya pesaing produk sejenis. 
3. Alternatif Strategi yang dapat digunakan untuk pengembangan usaha produk di Amelia Bakery Kabupaten Tabanan yaitu:

a) Meningkatkan kualita sproduk

b) Memperbanyak varian/jenis produk yang dipromosikan

c) Mempertahankan dan menjaga konsistensi mutu produk

d) Pelatihan pengolahan/produksi untuk tenaga pengolahan/produksi

e) Membuat kemasan yang lebih menarik dari produk lainnya

3. Berdasarkan hasil perangkingan alternatif, dapat diketahui bahwa alternatif strategi ketiga memiliki nilai preferensi sebesar 0.680. Sehingga dapat diambil keputusan bahwa alternative ketiga yaitu mempertahankan dan menjaga konsistensi mutu produk, merupakan prioritas strategi pengembangan usaha pada UD. Amelia Bakery Tabanan.

\section{Saran}

Saran yang dapat diberikan berdasarkan hasil penelitian yang telah dilakukan yaitu UD. Amelia Bakery dapat menggunakan strategi pengembangan berdasarkan alternatif-alternatif yang dipilih serta dilakukan lagi evaluasi-evaluasi sehingga strategi yang diterapkan dapat berjalan dengan baik. Menerapkan strategi yang telah diperoleh yaitu meningkatkan kualitas produk, memperbanyak varian/jenis produk yang dipromosikan, mempertahankan dan menjaga konsistensi mutu produk, pelatihan pegolahan/produksi untuk tenaga pengolahan/produksi, membuat kemasan yang lebih menarik, menguatkan kerja sama dengan pihak pemasok.

\section{DAFTAR PUSTAKA}

Amstrong, Gary dan P. Kotler. 2002.Dasardasar Pemasaran. Edisi 5, Jilid 2. Intermedia Jakarta.

Swastha, B. 2008. Menejemen Pemasaran
Modern. Edisi 2. Penerbit Liberty Yogyakarta.

David, F. R. 2005. Manajemen Strategis: Konsep. Salemba Empat Jakarta.

Dewi, K.V., L.P. Wrasiati, dan K. Satriawan. 2015. Strategi Pengembangan Usaha Produksi Roti Bali Kencana Bakery, Denpasar. Jurnal Rekayasa dan Manajemen Agroindustri. 3(4): 41-50.

Guiltinan dan P. Joseph.1994 . Strategi dan Program Pemasaran. Edisi 2. Erlangga Jakarta.

Hamel dan Prahalad. 2003. Management.New Delhi: Tata McGraw Hill.

Jauch, L. R. dan W.F. Glueck. 1991.Manajemen Strategis dan Kebijakan Perusahaan, EdisiKedua. Erlangga Jakarta.

Kotler, Philip. 1994. Marketing management: Analysis, Planing, Implementation, Control. Ed. 8, New jersey: Prentice Hall, Inc.

Nugroho, A. 2016. Analisis Strategi Pemasaran dengan Menggunakan Metode Quatitative Strategi Planning Matrix (QSPM) Pada Usaha Mebe ( Studi Kasus di PT. Wirasindo Santakarya-Wisanka). Fakultas Teknik. Universitas Muhammadiyah Surakarta. Skripsi. Tidak dipublikasikan.

Olson, D. L. 2004. Comparison of Weights in TOPSIS Models. Mathematical and Computer Modelling. 4 (1) : 721-727.

Rangkuti, F. 2005. Analisis SWOT Teknik Membedah Kasus Bisnis. PT. Gramedia Pustaka Utama Jakarta.

Safitri, N. M. R., A. A. P. A. Suryawan dan I. W. G. S. Yoga. 2017. Strategi Peningkatan Daya Saing Usaha Produk Skala Rumah Tangga (Studi kasus Rosana Bakery Desa Buruan 
Kecamatan Penebel, Kabupaten Tabanan, Bali) Jurnal Rekayasa dan Manajemen Agroindustri. 5 (3) : 57-65.

Setiadji, P dan D. Harjamti. 2013. Pengelolaan dan Pengembangan Usaha Pengolahan Roti pada PT.XXYZ di Depok. Agora 191.

Trisnayanti, N. M., K. Satriawan, dan I. W. G. S. Yoga. 2019. Strategi Pengembangan Produk Agroindustri Pada Area Belanja Agrowisata di Kabupaten Tabanan. Jurnal Rekayasa dan Manajemen Agroindustri. 7 (2) : 220-228.
Umar, H. 2003. Strategic Management in Action, Cetakan Ketiga. PT. Gramedia Pustaka Utama Jakarta.

Windarto, A. P. 2017. Implementasi Metode TOPSIS dan SAW dalam Memberikan Reward Pelanggan. Kumpulan Jurnal Ilmu Komputer. 4(1):88-99.

Yoon, K dan C.L. Hwang. 1981. Multiple Attribute Decision Making: Methods and Applications. Springer-Verlag. New York. 